\title{
Aprendizagens num Percurso de Autonomias e Poderes O Processo de Realojamento em Cascais ${ }^{1}$
}

Maria João Freitas *

\begin{abstract}
$\mathrm{R}$ linhas estratégicas delineadas para a prossecução do PER em Cascais e do processo que sustentou a sua formulação. Numa segunda parte serão sobretudo os detalhes de aprendizagem e de desenvolvimento de autonomias e poderes que a sua prossecução implicou que serão objecto de apresentação e análise no quadro da promoção de um desenvolvimento sustentável de qualidade e cidadania. Transversalmente a estas duas partes serão evidenciados alguns aspectos técnico-metodológicos que foram sustentando a formulação e consolidação dos novos saber-fazer inerentes a esta aprendizagem.
\end{abstract}

Palavras Chave: habitação; realojamento; processos de intervenção; participação; poderes

"Les opérations de développement social des quartiers s'attaquent à des situations sociales complexes nécessitant la mise en oeuvre d'approches nouvelles, la modification des pratiques professionnelles et du fonctionnement des organisations, mais aussi des manières de penser. Cela implique de réaliser des diagnóstics, pour approfondir la compréhension de ces situations et élaborer des projets d'action en vue de les modifier. Il ne s'agit donc pas seulement d'analyser les problèmes, mais d'examiner les possibilités de les resoudre et de conduire les diagnostics de manière à créer les conditions favorables à la mise en oeuvre des projets. C'est en ce sens que l'on peut parler de diagnostic dynamique, confrontant les points de vue des differents acteurs et associant l'examen des problèmes à l'analyse des organisations qui les prennent en charge. Ainsi, on peut faire du diagnostic le support de l'apprentissage de la coopération entre les acteurs."

(Bonetti, 1991)

\section{Notas Prévias}

Em 1995 foi iniciado em Cascais um processo de busca de inovação na forma de conduzir e desenvolver um projecto de intervenção no quadro do PER (Programa Especial de Realojamento DL163/93 de 7 de Maio), cujo Protocolo de Adesão tinha sido assinado em Janeiro de 94.

O GES/LNEC recebeu um convite do Gabinete PER para acompanhar a montagem e o desenvolvimento da implementação do Programa no concelho. A braços com dúvidas quanto à melhor maneira de optimizar o Programa, e sobretudo com certezas quanto ao que pretendia evitar, este Gabinete começou por solicitar recomendações e directivas quanto ao que poderia ser o melhormodus operandi a implementar na prossecução do Progra- ma. Em resposta a esta solicitação foi lançado o desafio de implementação de uma metodologia de programação generativa, inspirada nos trabalhos realizados por Michel Bonetti, em Paris, no CSTB/ Departamento de Sociologia Generativa.

Um dos pressupostos básicos desta metodologia consistia numa abordagem processual das dinâmicas sobre as quais se pretendia intervir e no acompanhamento de diagnósticos operativos e contínuos sobre essas dinâmicas, incluindo as dinâmicas organizativas e a operacionalização em saber-fazer dos princípios, cenários e estratégias que viessem a ser definidos. Um outro pressuposto implícito a esta metodologia era o seu desenvolvimento numa proximidade participativa entre os técnicos que a monitorizavam e os operadores dos programas. Ou seja, um pressuposto de que a produção de instrumentais de diagnóstico, planeamento,

\footnotetext{
* Socióløga, Investigadora Auxiliar, Grupo de Ecologia Søcial, Laboratório Naciønal de Engenharia Civil. Contacto: mjfreitas@lnec.pt

' Este artigo foi baseado na Tese de Doutoramento intitulada "Habitação e Cidadania - no trilho da complexidade de processos relacionais generativ $\bullet "$, ISCTE, 2001
} 
programação e avaliação a que ela poderia dar origem deveria ser uma produção conjunta com os responsáveis políticos e técnicos do Programa.

O desafio foi aceite e deu-se início à produção do que viria a ser uma experiência de investigação orientada para a acção, desenvolvida no seio dos meandros em que essa mesma acção se ia desenvolvendo. Esta experiência merece uma atenção especial quanto a dois aspectos:

a) A postura e o papel desenvolvido em termos de uma prática sociológica;

b) As especificidades dos instrumentais metodológicos e técnicos que a suportaram.

\section{Uma prática sociológica}

Em primeiro lugar, tratou-se de construir um papel de isenção e objectividade num contexto que poderia vir a ser equacionado como o de apoio à decisão. E esta construção, diga-se, em tudo se assemelhou a um processo contínuo de aprendizagens ao qual obviamente o perfil dos interlocutores em que este se actualizava não pode ser, de todo, negligenciado.

Foi um processo de aprendizagem e construção generativa na interlocução e na vontade da optimização dessa mesma aprendizagem, partilhada com o cliente. Ou seja, a exigência de isenção e objectividade analítica era o que se esperava desse desempenho, e nela residia a mais-valia da sua requisição por parte do cliente, não obstante ela implicar dificuldades ou exigências subjacentes às suas consequências para o bom desenvolvimento do Programa.

O resultado desta aprendizagem generativa fomentada na relação com a equipa técnica cliente proporcionou simultaneamente a sua cultura, e consequentemente esta aprendizagem funcionou como estímulo para o desenvolvimento da missão e para uma actualização e reflexividade permanente sobre o trabalho científico e técnico envolvido.

A marcar esta postura e esta aprendizagem há a relevar a permanente necessidade do cultivo e desenvolvimento de instrumentais de diagnóstico e avaliação (de que se dará conta mais pormenorizadamente adiante) mas também do desenvolvimento - sobretudo nas primeiras fases desta consultoria - de um papel de facilitação/mediação na compreensão e activação de dinâmicas processuais e relacionais a incentivar ou a contemplar na intervenção.
Sobre o papel de facilitação importa determo-nos sobretudo em dois aspectos: por um lado a sua dimensão cognitiva e por outro a sua dimensão pedagógica.

Do ponto de vista cognitivo, esta facilitação permitiu sobretudo abrir portas à compreensão do funcionamento de muitas dimensões "escondidas" nos processos de construção e desenvolvimento de quadros de acção generativos, de reacção e promoção de mudanças e das temporalidades que lhe são subjacentes. Permitiu ainda descortinar processos e trabalhar detalhes em múltiplas situações; "experimentar" instrumentais técnicos e avaliar a sua validade; avançar na compreensão das relações sociais e das relações humanas; questionamentos novos e buscas incessantes de resposta aos seus desafios.

Em decorrência, permitiu "crescer" do ponto de vista técnico e científico na construção de uma prática sociológica, por todos desejada e começada a ser compreendida também nas suas especificidades e vantagens. E é neste sentido que pode ser lembrada a dimensão pedagógica a propósito do desempenho deste papel de facilitação. De facto em várias ocasiões o ónus do sucesso ou insucesso de alguns processos recair na figura do desempenho deste papel no sentido de viabilizar as dinâmicas em curso, o que estava em causa era o desejo de "experiências" de novas formas de fazer e saber-fazer em novos contextos de relação em que esta facilitação apenas serviu à viabilização da sua sustentabilidade e desenvolvimento autonómico.

Numa postura auto-avaliativa do desenvolvimento deste papel há a considerar que ele foi possível precisamente no quadro da "aprendizagem" que esteve inerente a todo o quadro de acção relacional que este processo acabou por envolver, quer no que proporcionou de aprendizagem activa no quadro da própria sociologia, quer no que viabilizou para a melhor compreensão e legitimação da sua pertinência quando aplicada.

\section{Instrumentais Metodológicos e Técnicos}

O trabalho de consultoria técnico-científica e de avaliação "on-going" levado a cabo junto do Gabinete PER da Câmara Municipal de Cascais ao longo de cinco anos envolveu, como não poderia deixar de ser, diferentes fases e diversos instrumentos, e sobretudo um acompanhamento presencial da emergência de processos organizativos e de 
condução de projectos, de acções de intervenção, de dinâmicas em desenvolvimento e de reflexão sobre os territórios e respectivas dinâmicas sócio-territoriais em causa.

Diagnósticos, avaliações e reflexão atravessam em mote o enquadramento aos diversos instrumentais técnicos desenvolvidos no âmbito desta consultoria de apoio à montagem e desenvolvimento de projectos de intervenção sócio-territorial quer para a promoção de informação, quer para a sua utilização e análise, quer para a produção de rotinas de reflexividade e programação generativa. Muitos destes instrumentos acabaram por ter uma formalização mais continuada, outros acabaram por ter sido produzidos de forma mais episódica ou com objectivos muito precisos, constando hoje do espólio instrumental e analítico da própria Equipa PER/CMC.

Subjacente à sua produção mantiveram-se sempre três objectivos: (i) a sua pertinência para a produção de informação necessária ao acompanhamento técnico-científico solicitado; (ii) a sua pertinência no quadro de produção de informação e rotinas de análise das diferentes equipas do PER (equipa central e equipas locais); e (iii) a sua agilização em termos de proporcionar a autonomia destas equipas no seu uso e apropriação.

As ideias seleccionadas para apresentar neste artigo decorrem dste percurso e destas experiências e aprendizagem. Neste sentido este texto pretendeu dar conta de algumas especificidades a reter de projectos de intervenção desta natureza. Ou seja, de projectos nascidos com uma preocupação reflexiva e construídos em processos generativos de desenvolvimento de relações e de aprendizagens conducentes à autonomia e desenvolvimento de "empowerments" vários. Das múltiplas sínteses reflexivas desenvolvidas reteve-se a análise que se apresenta.

\section{O PER Cascais}

“PERspectiva, PERfazer, Mais-PERto" (CMC)

Cascais é um Município da Área Metropolitana de Lisboa com um território de aproximadamente $97 \mathrm{Km}^{2}$ e cerca de 170000 habitantes. É um território marcado por assimetrias entre a sua costa e o

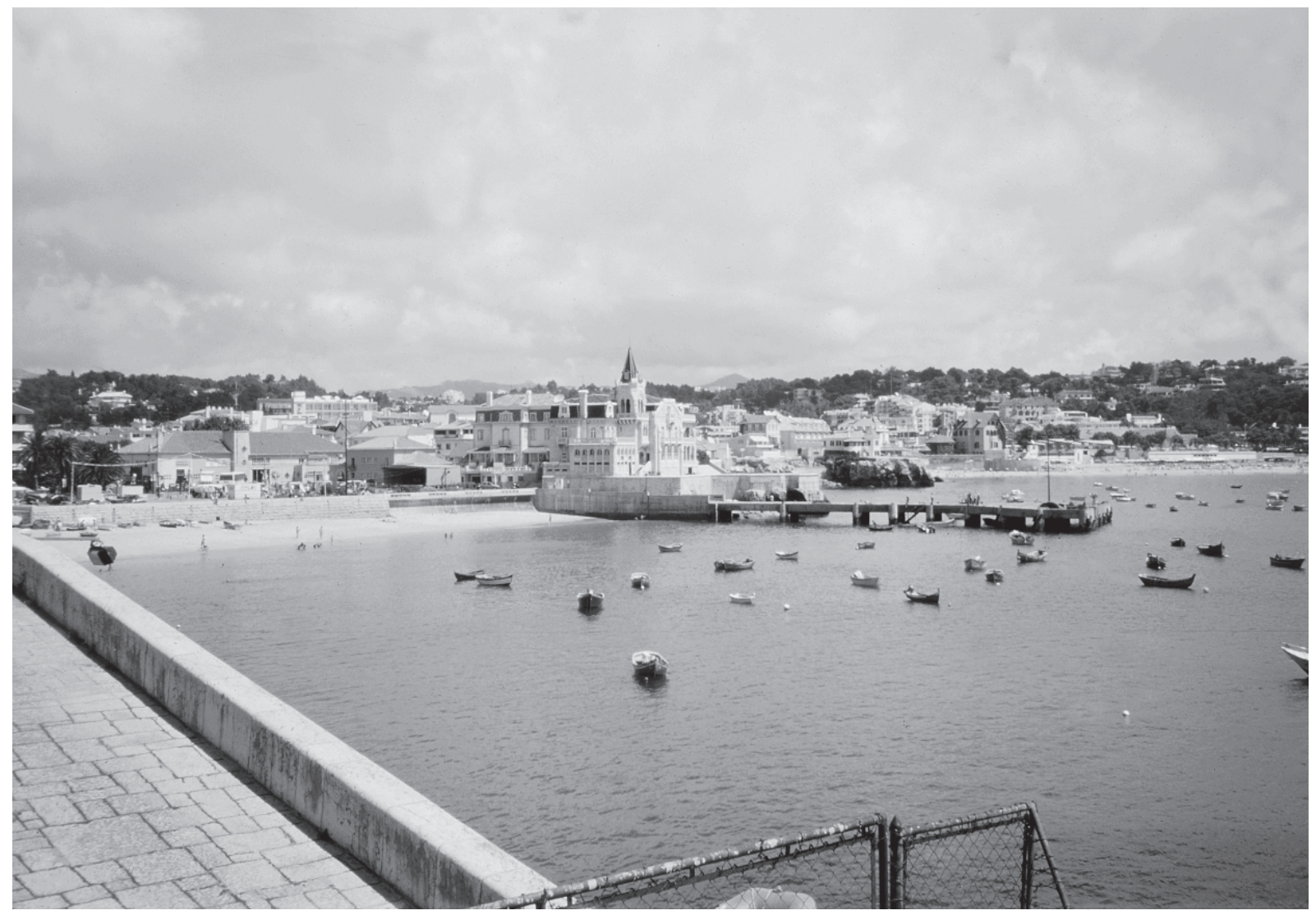

Foto de Maria João Freitas 
seu interior cuja ocupação responde a perfis diferenciados. Enquanto que a sua costa se desenvolve em torno dos serviços da linha de caminhos-de-ferro e da sua beleza natural, atraindo residentes e turistas, o seu interior apresentava até à última década uma ocupação ainda rural que foi desenvolvendo a sua atractibilidade com a implementação de algumas indústrias (actualmente sobretudo vocacionadas para o ramo electrotécnico) e com a construção da auto-estrada que liga o concelho à capital.

Apesar de Cascais apresentar índices de desenvolvimento comparáveis com os países mais ricos da Europa, as suas assimetrias convidavam a uma leitura mais precisa das suas realidades ecológicas, e sobretudo a um olhar mais atento à forma como a implementação de um Programa de Realojamento, como o PER, se deveria confrontar com estas mesmas realidades.

Em 1993 foram recenseadas cerca de 1300 barracas em cascais e cerca de 2050 famílias a abranger pelo PER. Ao contrário de outros concelhos, Cascais apresentava uma distribuição específica destas barracas que sugere uma leitura no quadro do próprio processo de desenvolvimento do seu território. E esta especificidade advém do facto de ser uma estrutura dispersa, com predominância de núcleos de reduzida dimensão, mas com uma concentração relativa de certa de $40 \%$ do seu contingente em dois núcleos com respectivamente 338 e 207 barracas no litoral, junto à linha de caminho de ferro - o Bairro das Marianas (cf. Freitas et al, 1995b) e a Quinta das Tainhas (cf. Freitas et al, 1996), respectivamente.

Se os núcleos dispersos no interior do concelho quase se confundiam com o processo de progressiva industrialização deste território, os núcleos localizados no litoral do concelho participavam igualmente do processo de atractibilidade que esta costa apresenta no conjunto do desenvolvimento da Área Metropolitana. E esta atractibilidade dava pelo nome de vantagens relativas de acessibilidade, oferta de trabalho que propicia na área da industria hoteleira, serviços domésticos e na área da construção civil que acompanhou o seu rápido crescimento populacional nas últimas décadas. Também, do ponto de vista sócio-demográfico seria no interior do concelho que se encontrariam as famílias mais idosas e com maior tempo de fixação nas barracas, enquanto que no litoral predominavam os contin-

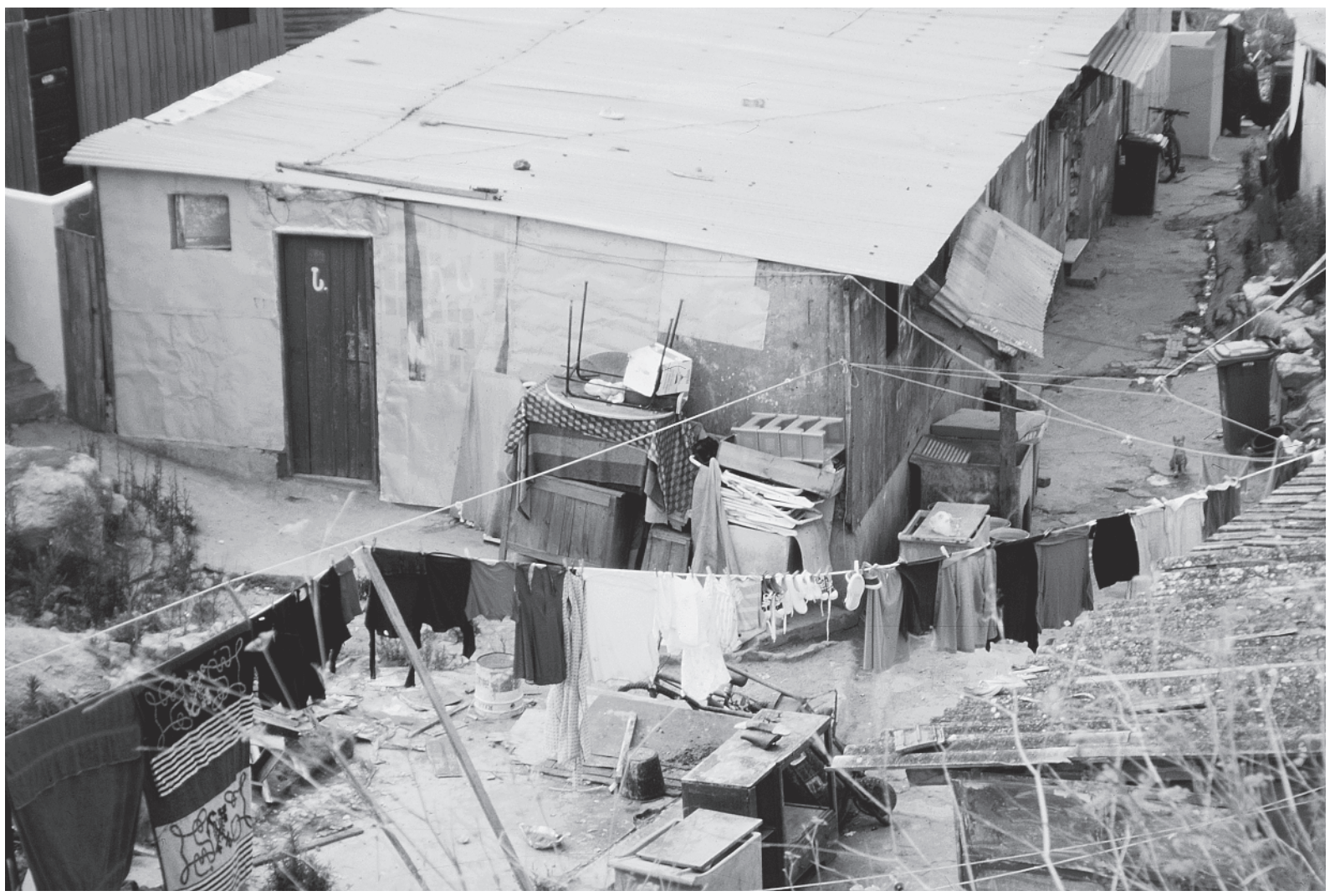

Foto de Maria João Freitas 
gentes populacionais participantes de movimentos migratórios mais colectivos (como o retorno das ex-colónias nos finais dos anos 70, ou os reflexos de processos de imigração dos Palop's dos anos 90).

O concelho de Cascais, envolvido já em anteriores experiências de realojamento, com o recenseamento que baseou a sua candidatura e assinatura do Protocolo de Adesão ao PER, descobre, no entanto, a dimensão e as características desta sua realidade social, em arrepio da imagem generalizada de bem-estar e qualidade de vida que o concelho apresentava. Com esta consciencialização, a oportunidade atribuída ao Programa para a participação e desenvolvimento das potencialidades locais, mobilizou a autarquia para encetar um longo caminho que se veio a balizar pela optimização e inovação da sua actuação no âmbito da promoção e dinamização de processos de desenvolvimento social local (cf. Freitas, 1995a).

Passados cerca de sete anos do início deste processo, importará aqui realçar o que de aprendizagem de produção de autonomias e de poderes tem vindo a implicar, tanto no que respeita à sua estrutura promocional, como das estruturas sócio-espaciais com que se actualiza, em sequência das opções estratégicas que tem prosseguido desde então.

Neste sentido, numa primeira parte deste artigo proceder-se-á a uma apresentação das principais linhas estratégicas delineadas para a prossecução do PER em Cascais e do processo que sustentou a sua formulação. Numa segunda parte serão sobretudo os detalhes de aprendizagem e de desenvolvimento de autonomias e poderes que a sua prossecução implicou que serão objecto de apresentação e análise no quadro da promoção de um desenvolvimento sustentável de qualidade e cidadania. Transversalmente a estas duas partes serão evidenciados os aspectos técnico-metodológicos que foram sustentando a formulação e consolidação dos novos saber-fazer inerentes a esta aprendizagem.

\section{Princípios, Cenários e Estratégias - o ponto de partida para uma aprendi- zagem generativa}

Em Janeiro de 1995 a Câmara Municipal de Cascais criou na sua estrutura um Gabinete Autó- nomo ao qual foi atribuído a responsabilidade de Programação e Gestão do PER, constando desde logo na redacção das suas competências e responsabilidades a intenção da liderança do Programa no quadro do desenvolvimento sócio-territorial, para além da sua vertente meramente promocional de novas habitações destinadas ao realojamento das famílias recenseadas.

Com uma equipa ainda reduzida, mas já multidisciplinar, o Gabinete PER com o objectivo de reduzir e anular efeitos não desejados com experiências de realojamento anteriores, e visando uma optimização do Programa para a qualificação do concelho, decidiu promover um conjunto de sessões de discussão ${ }^{2}$ sobre esta temática, tendo delas resultado o enunciado de princípios, cenários e estratégias a prosseguir.

A definição desses princípios, cenários e estratégias deu origem a um documento (Freitas, 1995a) que para além de sintetizar as linhas orientadoras para a implementação do Programa passou a constituir uma base de trabalho quer no desenvolvimento de metodologias para a sua operacionalização, quer no envolvimento de forças políticas, institucionais e das populações na sua discussão e participação na prossecução dos seus conteúdos.

Sinteticamente este documento postulava uma intenção de "considerar as realidades de intervenção como um todo, indissociável dos contextos institucionais, organizacionais e políticos, e obedecer a uma lógica de encontros e compromissos, num processo contínuo e dinâmico de reconhecimento de parcerias" (Freitas, 1995a:13), com vista ao desenvolvimento de um cenário de qualificação e desenvolvimento de autonomias e de promoção de um processo de desenvolvimento social local. Esta foi a missão proposta, discutida e rectificada politicamente para a prossecução do Programa, relativamente à qual foram delineados objectivos e estratégias globais.

Para além do realojamento das famílias recenseadas em barracas, pretendia-se, assim, tirar partido do Programa para iniciar um processo de desenvolvimento social e territorial, participado e sustentado.

Porém, importa contextualizar as circunstâncias em que estes postulados eram enunciados, uma

\footnotetext{
2 Estas sessões envolveram, numa fase inicial, sobretudo técnicos de várias formações e competências profissionais, tendo sido na fase final, alargada à participação do executivo camarário e à discussão pública.
} 


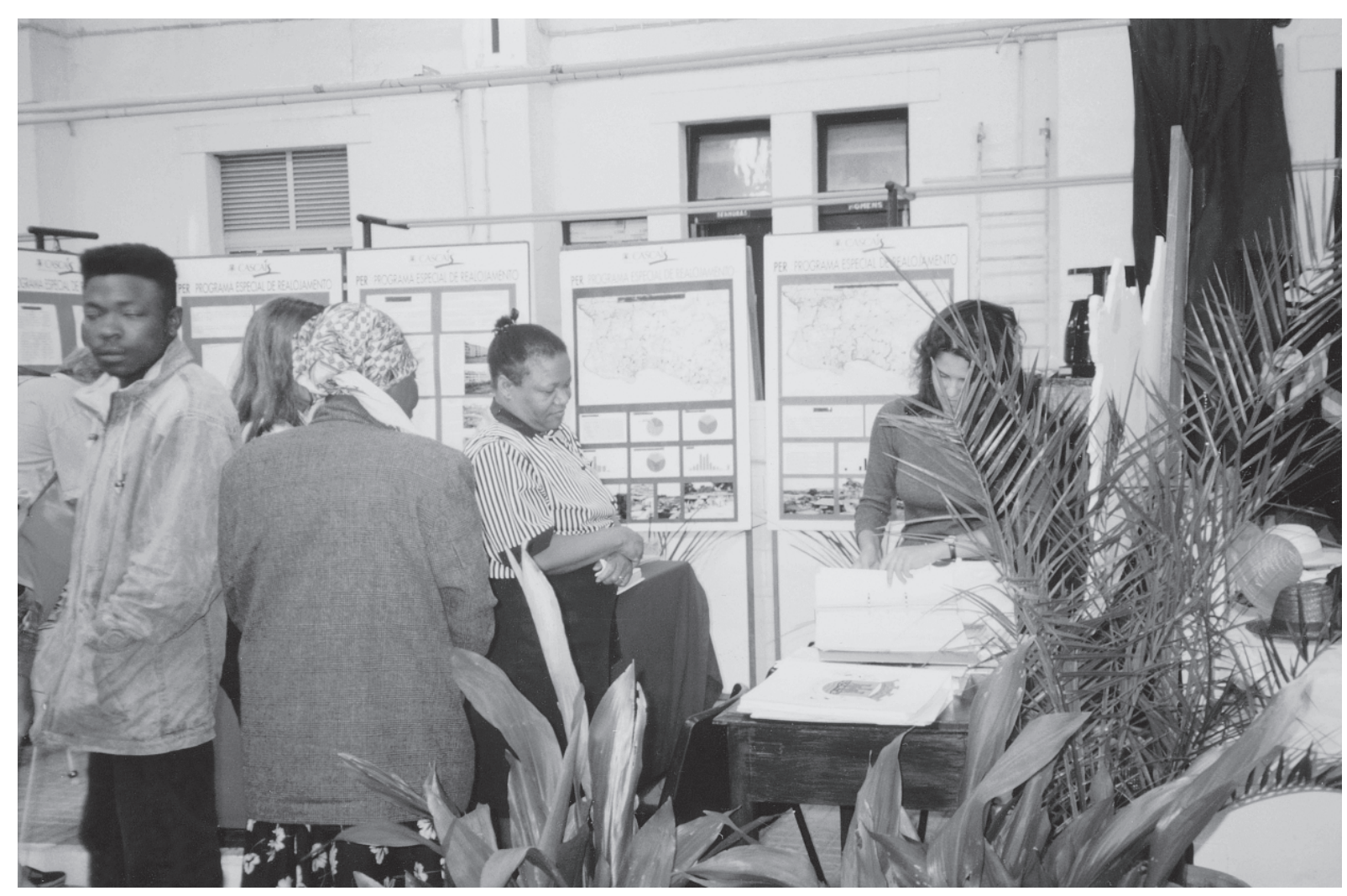

Foto de Maria João Freitas

vez que nos últimos anos se podem notar diferenças substanciais nesses contextos. Em 1995, a propósito dos processos de realojamento e da intervenção local motivada pelas questões habitacionais discutiam-se sobretudo os seus paradoxos (Freitas, 1994) num alerta de consciencialização de que "as pessoas não são coisas que se metam em gavetas" (Guerra, 1994). Esta frase que celebrizou o n. ${ }^{\circ} 20$ da revista Sociedade e Território (1994) viria a balizar todas as discussões posteriores, ao induzir uma operacionalização e identificação do que seria conducente a pôr em gavetas e do que seria não pôr em gavetas.

As experiências portuguesas conhecidas, e sobretudo as mais recentes, induzam à ilustração do que seriam exemplos de "pôr em gavetas". De fora, sobretudo de França, vinham relatos de consequências consolidadas e assustadoras destas opções e ilustrações do que poderiam ser estratégias diferenciadas (Bonetti, 1994). No entanto, havia que considerar as respectivas diferenças nas condições em que estes exemplos eram recrutados e sobretudo das condições em que os seus ensinamentos podiam ser potenciados e desenvolvidos.
Em França, iniciava-se a definição de uma Política das Cidades e as novas metodologias de intervenção ganhavam corpo na motivação de uma gestão sustentável de um parque habitacional consolidado, mas com manifestações de problemas graves de desqualificação sócio-territorial. Em Portugal, respondia-se ainda a uma urgência na intervenção na área habitacional, equacionada como área sectorial específica, carente de respostas ao nível de uma procura específica. De França vinham experiências de insucessos em larga escala e de tentativas de respostas e reparo numa fase pósconstrutiva de um parque habitacional de serviço público, sustentadas em vários anos de reflexão sobre o assunto e escudadas por mecanismos de respostas institucionais, organizacionais e organizativas já preparadas, ou em fase de reestruturação, para o confronto com estes desafios. Em Portugal, em contrapartida, tratava-se ainda de construir novo parque, sendo a reflexão ainda sobretudo marcada por alertas prospectivos de emergência de problemas e quase omissa em sensibilidades para as estruturas de resposta institucionais, organizativas e organizacionais. 
Estas, entre outras diferenças, viriam a evidenciar dois pontos de partida que acabariam por marcar o percurso reflexivo e a importância atribuída às diversas dimensões que este implicava. Por um lado, das experiências acumuladas ou importadas de outros contextos retirava-se sobretudo o que não deveria ser repetido. Por outro, a definição de respostas alternativas balizavam-se sobretudo por uma lógica preventiva e de médio ou curto prazo, projectadas no tempo, que não poderiam encontrar propriamente correspondência nem nas temporalidades de definição de respostas encetadas em França, por exemplo, nem nas premências e contextos que aí sustentavam o seu desenvolvimento.

Estes dois pontos de partida, se permitiam avançar na definição de visões e estratégias na sua generalidade, deixavam, no entanto, ainda pouco pressionantes os motivos que a elas podiam conduzir e sobretudo completamente em aberto a definição dos caminhos técnico-metodológicos para a sua prossecução. Eram, assim, desafios que se confrontavam simultaneamente com a possibilidade de potenciar o desenvolvimento de estratégias projectadas num tempo mais longo, mas cujas balizas de referência no seu modus operandi se encontravam sobretudo definidas no que haveria de evitar em heranças de um tempo anterior, e no que apenas a generatividade relacional e processual das suas dinâmicas poderiam vir a ditar.

Em Cascais estes desafios acabariam por ser equacionados precisamente numa lógica de opostos (Freitas 1995a, Freitas 1998), projectando intenções, e numa lógica de negação, mais do que de proposição de saberes-fazer concretos a accionar. A saber:

- promover desenvolvimento social e urbano, por oposição a soluções de fachada;

- promover qualidade, por oposição à viabilização de situações de deterioração e estigmatização social e urbana;

- envolver a participação de todos os recursos materiais, humanos e ecológicos, por oposição ao seu desperdício;

- optar por lógicas de planeamento estratégico, por oposição a visões a curto-prazo;

- apostar na sustentabilidade, por oposição a medidas imediatistas;

- apostar numa análise global de custos e investimentos, por oposição a uma gestão de despesas a curto-prazo;
- apostar em mecanismos de comunicação e informação, por oposição a respostas a efeitos surpresa;

- desenvolver uma gestão global e integrada de recursos, por oposição a respostas ineficazes e ineficientes.

É neste contexto de potenciação de um momento privilegiado para inverter lógicas de intervenção que surge o enunciado das sete estratégias que viriam a sustentar a construção e o desenvolvimento de um processo de intervenção (Freitas, 1995a):

1. Compreender para Intervir

2. Diagnosticar, Programar e Avaliar para garantir eficiência e eficácia.

3. PER: Instrumento Estratégico para alargar os campos de intervenção.

4. Organizar Parcerias para potencializar sinergias.

5. Apostar na Qualidade Arquitectónica e Urbanística.

6. Apostar na Informação e na Comunicação

7. Apostar na Inovação ao nível dos saber-fazer.

Estas sete estratégias baseavam-se num pressuposto de base que remetia para a natureza relacional e processualmente generativa das dinâmicas com que a implementação do Programa se iria confrontar, e de que iria ser simultaneamente contribuinte e tributário.

Este pressuposto comportava duas consequências estruturantes à própria montagem e prossecução do Programa.

A primeira consistia no facto da sua concepção e desenvolvimento se sustentar no conhecimento, reconhecimento e envolvimento da complexa teia de actores e factores que participavam na construção das realidades e das dinâmicas com que ia lidar, fossem eles de natureza social, espacial, organizacional ou política. E a consequência deste ponto de partida exigia sobretudo uma abertura atenta e sistemática quer à manifestação e posição relativa destes actores e factores no quadro do sistema de acção, quer ao acompanhamento sistemático das suas dinâmicas, para as quais a própria acção encetada ou desenvolvida no quadro do Programa importava considerar.

Tratava-se, assim, de considerar que ao partir das realidades e dinâmicas locais se estava peran- 
te o desafio de uma construção dinâmica e generativa de um processo, a acompanhar e actualizar dia-a-dia no seu próprio desenvolvimento. Aprópria acção técnica e política no quadro do Programa e no quadro de toda a actividade interventiva, não era apenas nem o actor principal, nem tão-pouco um mero espectador, mas um participante activo, entre outros.

A segunda consequência destes pressupostos relacionais e generativos de um processo, consistia no facto de, quer inerente a esta natureza, quer decorrente de uma inexperiência generalizada do seu reconhecimento, se estar face a um situação nova, e exigente em inovação, de processos operativos ao nível dos saber-fazer. Ou seja, às exigências de generatividade dos processos, acrescia uma inexperiência que se poderia considerar alargada a todo o sistema de acção em se reconhecer como tal e em funcionar como tal.

E esta consequência remetia para um processo de aprendizagem colectiva nas lideranças e participações inerentes à construção dessas dinâmi- cas, que poucas referências de cartilha possuía. Era uma aprendizagem nova, em que todos os actores se iriam ver envolvidos e que iria depender, à falta de outros referentes, sobretudo das experiências que viessem a ser vivificadas e dos resultados de um processo relacional complexo, dinâmico e sobretudo sujeito a temporalidades diferenciadas na sua consolidação.

Tratavam-se assim de uma dupla de desafios bastante exigentes conducente a um objectivo igualmente ambicioso, aqueles que neste quadro de enunciados e vontades estavam presentes. Tratava-se também de uma ruptura relativamente a processos anteriormente encetados que importava legitimar e fazer vingar na sua capacidade generativa de promoção de processos alternativos, credíveis e viáveis na criação de dinâmicas vivenciais ou potenciais de novas positividades.

O seu sucesso, no entanto, ficava muito mais dependente das vontades e das participações de todos nestes desafios e na criação de novos sentidos e orientações às dinâmicas processuais e

Figura 1 - Guia de Orientação para a Orquestração do Programa de Realojamento

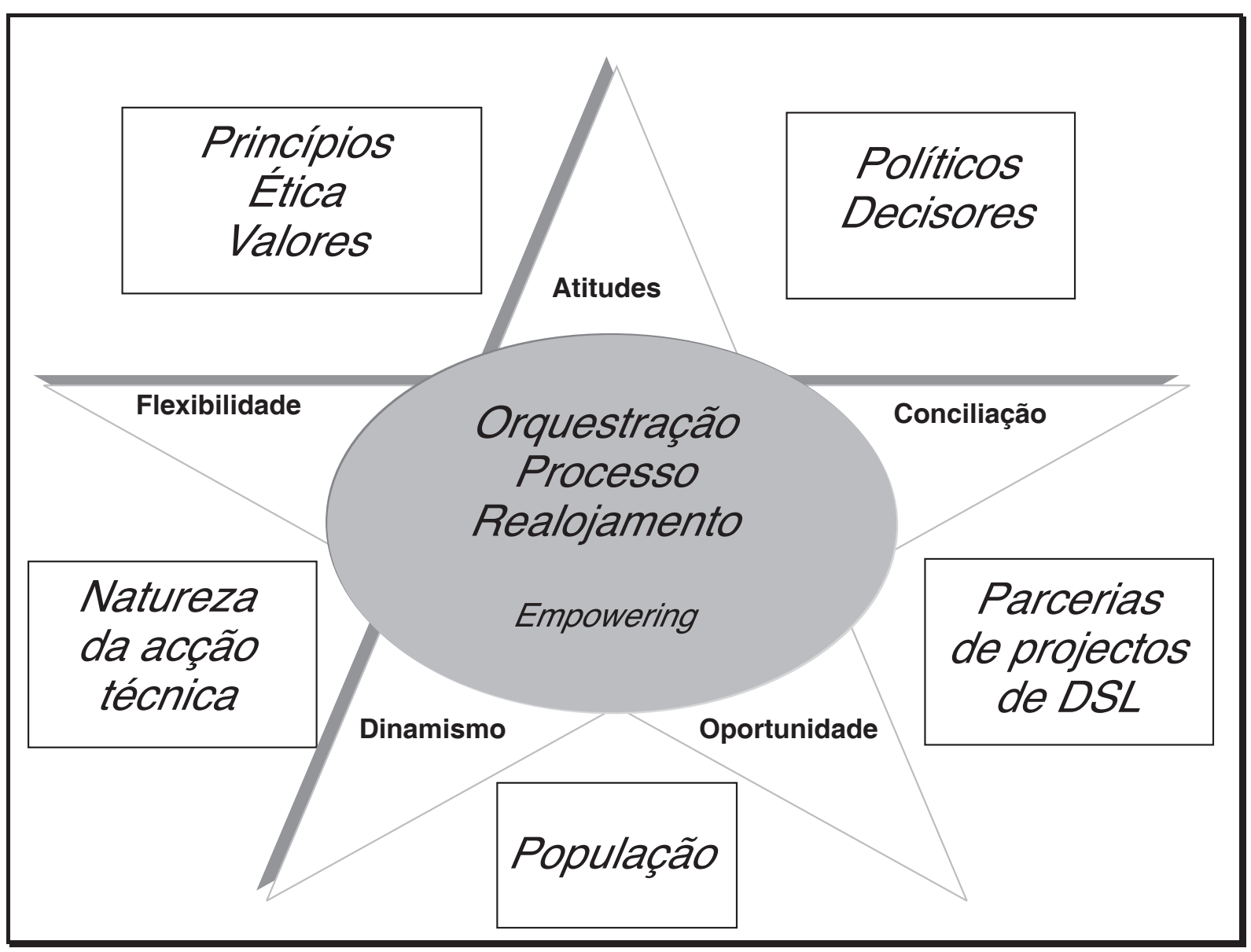


relacionais em que se encontravam, do que da certeza de procedimentos ou da sua pré-definição detalhada. Tratava-se, então, de uma aposta a construir na proficuidade das aprendizagens que exigia, na perseverança e crédito atribuído aos seus princípios orientadores, e na atenção, reconhecimento, dinamização e participação activa de um leque bastante alargado de actores, ou seja, na proporcionalidade do risco da sua novidade e da sustentabilidade das suas promessas.

\section{Apontamentos de Leitura de um Processo Generativo e Relacional de Produção de Autonomias e Poderes}

\section{Um documento}

Este documento onde tinham sido sintetizados os princípios, cenários e estratégias a prosseguir pelo PER/Cascais, à época, provocava simultaneamente dois sentimentos ambivalentes transversais à grande maioria dos actores que com ele se foram confrontando, quer na sua construção, quer na sua validação, quer na participação e envolvimento no Programa a que convidava.

Por um lado, representava uma utopia, pelo parco que era ainda em instrumentos de operacionalização, e pelo convite que dirigia sobretudo a uma construção generativa de um processo de aprendizagens mútuas, sem receitas predefinidas, na exigência da participação de muitos e diversos actores numa teia complexa de relações a construir no decorrer da sua própria dinâmica. Representava, assim, simultaneamente um desafio definido numa optimização de resultados que podiam ser esperados com esta operação e um "salto" para um indefinido, cujas fronteiras eram mais balizadas pelo que se devia evitar, em termos de procedimentos, do que por certezas de um processo, esse, completamente aberto e dependente da dinâmica da sua própria generatividade relacional.

Por outro lado, provocava também a ambivalência entre um fascínio e o medo, uma esperança e uma insegurança; uma vontade partilhada e um descrédito na partilha dessa mesma vontade para a sua realização; o reconhecimento da necessidade de inovar ao nível dos saber-fazer e dos fazeres e a fragilidade e insegurança face a um processo de aprendizagem por construir.

A ruptura que implicava com procedimentos anteriores da própria autarquia ou que se tinham vindo a generalizar na prática destes processos de intervenção noutros locais, assustava, provocando um descrédito preventivo, não no que era partilhado e procurado nas suas intencionalidades, mas sobretudo na capacidade de pôr em prática os novos procedimentos.

Eram estes os sentimentos que foram marcando transversalmente o processo de reconhecimento das intencionalidades e escolhas estratégicas que progressivamente iam ganhando corpo. Esta fase de desenvolvimento do Programa viria, no entanto, a revelar-se como estruturante e sedimentadora do seu próprio arranque.

A importância atribuída à discussão e divulgação ${ }^{3}$ destes princípios, cenários e estratégias acabaria por ajudar a construir, se não ainda uma confiança nos resultados a obter com as novas linhas orientadoras do Programa, pelo menos uma linguagem e um entendimento concertado, ao nível discursivo, para a sua prossecução. A discussão e comunicação a que este documento foi sujeito representava simultaneamente um compromisso, por parte da autarquia, mas também a viabilização de um primeiro instrumento de recursos disponível a todo o sistema de acção.

Precisamente pela sua natureza aberta, era um instrumento de recursos que viabilizando uma concertação ao nível da mobilização das vontades e intenções, deixava ao critério do próprio sistema de acção que se começava a construir no reconhecimento mútuo dos seus elementos, uma grande margem de liberdade na sua utilização. Neste sentido, esta fase de arranque do Programa permitiu a formulação de todas as dúvidas, medos, inseguranças, ao mesmo tempo que permitia a consolidação dos contornos gerais para a sua resolução ou ultrapassagem ao permitir um acesso alargado à sua construção.

\section{A construção}

A construção do processo pressupunha, como foi anteriormente referido, o envolvimento e o

\footnotetext{
Esta discussão e divulgação foi feita junto da comunidade técnica (da autarquia e outros serviços institucionais e/ou organizativos), política (nos vários órgãos de representação local e com os diversos partidos políticos), e das comunidades locais (população a realojar, população das áreas de acolhimento e população geral do concelho).
} 
reconhecimento de um sistema de acção cuja dinâmica dependia da sua própria generatividade, ou seja, da consolidação de um sistema relacional para o qual a participação de todos os seus elementos se demonstrava imprescindível na definição do seu próprio poder de actuação e na definição da sua dinâmica. E enquanto sistema relacional, dependia igualmente do reconhecimento da liberdade e capacidade autonómica de cada um dos actores na sua construção, consolidação e gestão, ou seja, do reconhecimento de um jogo de acção e da capacidade participativa dos seus actores não apenas no desempenho dos papéis escolhidos, mas também na definição e validação das regras com que esse sistema podia contar na agilização do seu funcionamento.

Tudo era novo, tanto para os actores institucionais como para os restantes actores participantes, exigindo uma aprendizagem relacional na superação de medos e ganhos de confiança nesse processo construtivo. Quanto às especificidades desta aprendizagem, retomar-se-á adiante a sua apresen- tação e análise. Retenha-se por hora dois aspectos que se revelaram fundamentais ao alicerçar desta construção: (i) a angariação de confiança no processo e (ii) a mobilização e dinamização da sua própria acção na gestão de diferentes temporalidades de referência e actuação em presença.

Foi dito anteriormente que o trabalho de discussão, divulgação e validação do documento dos princípios cenários e estratégias tinha viabilizado e disponibilizado um recurso importante para a concertação de vontades, deixando, no entanto, por superar uma certa partilha de descrédito na sua prossecução, fazendo evidenciar sobretudo dúvidas e receios quanto à sua viabilidade.

O processo de credibilização quer das vontades enunciadas quer da sua viabilidade actuante foi um processo que apenas foi sendo consolidado com a própria prática e experiência dos processos relacionais que se iniciaram e que foram progressivamente alimentando novas seguranças à sua prossecução e desenvolvimento. Importa referir que a maior parte deste processo se foi consolidando

Figura 2 - Exemplo de grelha utilizada na análise e avaliação on-going da implementação do projecto

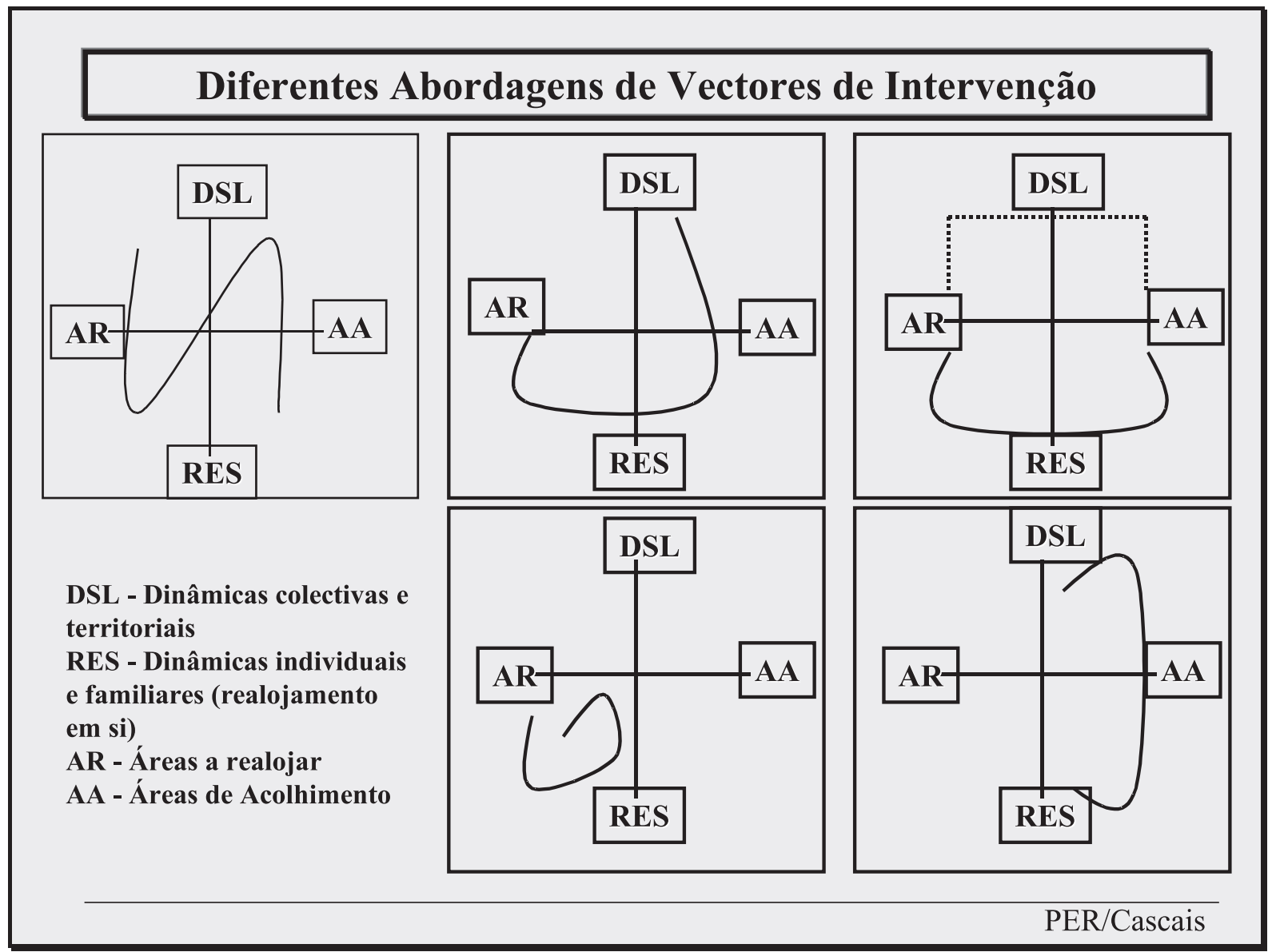


em registos de fraca visibilidade, tendo necessitado de tempo para ser reconhecido nas suas expressões relacionais e nos seus próprios resultados.

Um exemplo ilustrativo deste processo pode ser retirado da forma como o próprio poder foi sendo reconhecido, apropriado, partilhado e produzido no seio destes sistemas relacionais. Em quase todos os momentos iniciais deste processo, o poder (de fazer, de participar, de comunicar, de....) começou por ser entendido como um recurso que uns detinham e outros não e pela posse do qual, não obstante as intenções da sua partilha, seria necessário lutar ora para sua manutenção ora pela sua conquista. Técnicos e políticos que o detinham por inerência das suas funções legitimadas, ao pretenderem partilhá-lo nem sempre sabiam como fazê-lo, receando, no entanto, vir a perdê-lo. Outros técnicos e a população em geral, detendo formas de poder que eram viabilizadas ou lhe estavam a ser externamente reconhecidas, não o reconheciam como tal, e portanto encetavam posições de anulação, resgate ou conquista no suporte de locus de controlo externos.

$\mathrm{O}$ processo de reconhecimento dos diferentes poderes em jogo e da sua capacidade de desenvolvimento nos sistemas relacionais encetados, foi assim, um processo que necessitou de dois movimentos essenciais à sua legitimação: o auto e o hetero-reconhecimento desses mesmos poderes e das suas expressões.

O processo de construção e legitimação do poder no seio destes quadros relacionais necessitou, assim, de um processo de consolidação do seu reconhecimento, no seio desses próprios sistemas. $O$ poder de actuação era uma definição vaga e, por isso, com dificuldades de ser reconhecida. Para ser auto e hetero-reconhecido, necessitou de ser formalizado, enunciado, exemplificado. Porém, para além dos momentos de formalidade em que estas formalizações e enunciados podiam ter expressão, este processo actualizava-se sobretudo em registos da sua prática informal, e em respeito, mas também persistência, pelas diferentes temporalidades que envolviam quer a sua expressão, quer o seu reconhecimento, quer mesmo a sua actuação.

Podem recordar-se, a título ilustrativo destes momentos, três experiências produzidas por este mesmo processo que acabariam por marcar quer o seu rumo, quer o seu crescimento enquanto pro- cesso generativo de novos poderes num quadro relacional e aberto à participação e ao exercício de poderes ${ }^{4}$.

Um primeiro exemplo retenha-se o primeiro processo de envolvimento das populações que decorreu no Bairro das Marianas. Este envolveu uma série de reuniões gerais e com grupos de trabalho específicos com as populações locais, que veio a dar lugar a uma frente de trabalho de recuperação de auto-estima e protagonismo a desenvolver por parte desta população. Esta experiência ilustra situações em que por vezes se registaram dificuldades em reconhecer estatuto merecedor de enunciação a determinados "poderes" existentes. Assim, por exemplo, se não era difícil para estes moradores identificar os problemas com que os seus territórios ou populações se confrontavam, já a identificação das suas potencialidades e factores positivos existentes e em exercício, se afigurava uma tarefa "silenciada" e quase "envergonhada". Neste caso, registava-se um hetero-reconhecimento destes poderes e este silêncio, viria a ser trabalhado no sentido de adquirir uma "fala", através de várias iniciativas promovidas tecnicamente com vista ao reconhecimento desses "poderes" por parte dos seus protagonistas (auto-reconhecimento dos moradores).

Um segundo exemplo encontra ilustração pormenorizada no acompanhamento da reacção da população de uma área de acolhimento (Trajouce) à construção de um empreendimento PER. Com um cunho inicialmente negativo, esta reacção foi potenciada após uma reunião de trabalho promovida pela autarquia para sensibilizar sobre a necessidade de uma participação alargada das populações e organismos operantes nas áreas de acolhimento. Neste caso a maior dificuldade inicial encontrada não remetia para déficits de auto e hetero-reconhecimento de poderes, mas sobretudo para um déficit de reconhecimento e legitimação dos canais de comunicação e participação que estavam a ser viabilizados e construídos para a sua activação integrante no processo. Terão sido o aprofundamento do desenvolvimento destes canais e a persistência na sua activação que vieram progressivamente a agilizar um ambiente mais favorável ao desenvolvimento do processo relacional que se prosseguiu e que acompanhou as fases seguintes.

\footnotetext{
${ }^{4}$ Relatos pormenorizados de alguns destes momentos e das suas consequências existem registados quer em relatórios produzidos pelo GES/LNEC no quadro do seu acompanhamento e avaliação on-going do processo, quer em documentos produzidos pela própria equipa do PER/Cascais.
} 
Figura 3 - Exemplo da grelha utilizada num Walktrough realizado em Trajouce com todos participantes no projecto (equipa técnica e política; população; parcerias das áreas de origem e de acolhimento)

\section{WT O Exercício em TRAJOUCE}

\begin{tabular}{|l|l|l|l|l|}
\hline & $\cdots$ & & & \\
\hline \hline alojamento & & & & \\
\hline \hline edifício & & & & \\
\hline \hline espaços exteriores & & & & \\
\hline rel.c/ envolvente & & & & \\
\hline
\end{tabular}
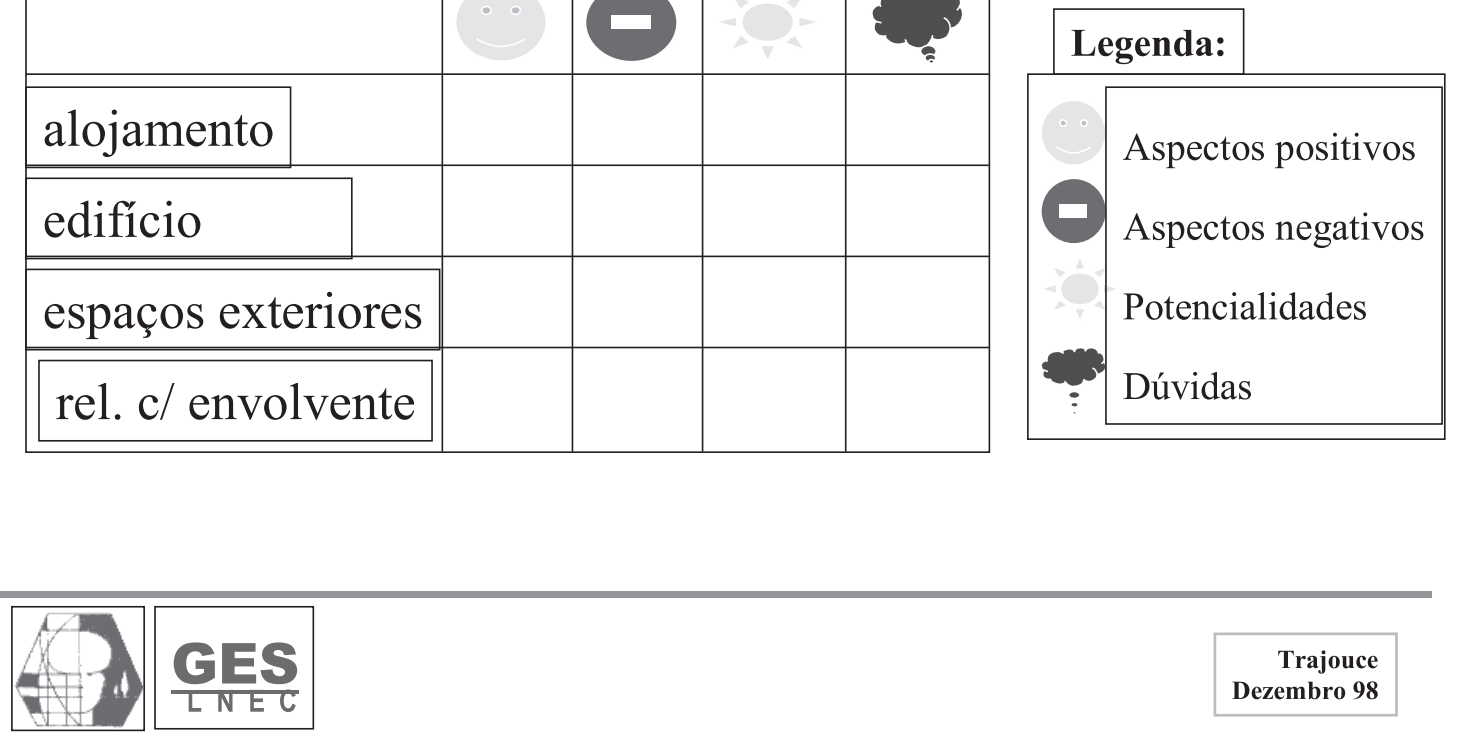

Uma terceira experiência reporta-se ao processo de dinamização de parcerias institucionais. Este exemplo decorre da experiência de contactos e activação de trabalho em parceria com outros actores institucionais, organizativos ou de representação colectiva, sobretudo na discussão e escolha das modalidades formais e informais que seriam susceptíveis de contribuir para a eficácia e eficiência da implementação do Programa. Estas deveriam ser medidas não apenas do ponto de vista da autarquia, mas no quadro do envolvimento e da participação destes actores nas vantagens e potencialidades que lhes poderiam ser igualmente sinergéticas na prossecução das suas missões. Nesta experiência o maior desafio consistiu no reconhecimento e legitimação de processos participativos nas suas práticas, para além das suas meras formalizações, e de vantagens sinergéticas e produtivas que poderiam ser conquistadas sem implicar necessariamente acréscimos de trabalho. Ou seja, o desafio remetia para o desenvolvimento e credibilização de novas formas de saber-fazer, e portanto de "empowerment" técnico e organizacional que viabilizasse a prossecução dos objectivos partilhados para o Programa.

A unir estas três experiências podem identificar-se cinco pontos de confluência:

a) o facto de em todas elas ter estado presente a necessidade de atribuir, reconhecer e legitimar conteúdos de exercício de poder, bem como das suas formas de manifestação;

b) o facto de todos estes processos terem conduzido a uma inversão na concepção de uso desses poderes, sedimentada na confiança que o sistema relacional conferia à generatividade do uso e exercício desses poderes;

c) o facto de estas três experiências terem produzido a sua própria generatividade com recursos a momentos de informalidade e formalidade na construção do sistema relacional em que participavam;

d) o facto de terem sido capazes de produzir instrumentos inovadores na sua regulação e 
actualização, baseados numa partilha generalizada das experiências de cada participante;

e) o facto de também em todos os factores espaciais e temporais, para além de referenciais à actuação do próprio sistema, terem passado a ser considerados como elementos activos na regulação e crescimento da construção generativa e relacional destes processos.

O processo de credibilização do sistema relacional a que a implementação deste Programa induziu, apresentou-se - e ainda se apresenta, não obstante os ganhos que já foi conquistando - como um processo construtivo, baseado em níveis cada vez mais elevados de exigência, à medida que lhe iam sendo reconhecidas também as suas potencialidades e as suas próprias produções. Ou seja, a sua capacidade de desenvolvimento, superada o reconhecimento das suas potencialidades, sustenta-se também na capacidade produtiva de poderes que comporta e das autonomias dos seus actores decorrentes dos processos de aprendizagem que envolve.

\section{A aprendizagem}

A aprendizagem que a implementação deste Programa e que a construção dos processos relacionais generativos implicavam foi, antes de mais, uma aprendizagem colectiva, que como foi anteriormente referido, assim se apresentava quer por inerência da natureza destes processos, quer pelo facto de ser uma experiência nova para a globalidade dos seus participantes.

Esta aprendizagem colectiva era também uma aprendizagem múltipla nos domínios que implicava. Tratava-se de uma aprendizagem ao nível da apropriação de novos conceitos, da construção e uso de novos instrumentais necessários à sua operacionalização, mas também se tratava de uma aprendizagem de olhares e fazeres, e de uma aprendizagem sobretudo balizada por exigências relacionais.

Havia ainda que reconhecer os sentidos dessas aprendizagens múltiplas. Se muitas destas aprendizagens se orientavam por sistemas de procura, muitas implicavam uma atenção reforçada no reconhecimento, teste e validação desses mesmos sistemas balizadores de uma procura.

As características destas aprendizagens apresentavam como desafio principal à sua consolidação a produção de experiências, em que o erro, não podendo ser evitável, não podia ser, no entanto, estagnável na busca de mais ou melhores soluções.
Fazer aceitar as limitações e o não perfeccionismo das tentativas construtivas do processo era, assim, uma condição basilar à sua prossecução em busca de novas ou melhores potencialidades ao seu desenvolvimento. A circularidade de informação, os mecanismos comunicacionais que foram sendo validados e o reconhecimento da participação dos vários elementos que contribuíam para a configuração destes sistemas relacionais foram elementos fundamentais à criação desta dinâmica e à incorporação dos erros ou das faltas no seu próprio processo generativo.

Outro desafio que estas aprendizagens apresentavam remetiam para a gestão das suas diferentes temporalidades nas suas diversas manifestações. Se era preciso tempo na consolidação destas aprendizagens, era também necessário fazer conciliar vários tempos no seu desenvolvimento, nas suas frequências, ritmos e lógicas de manifestação. No tempo se ganhavam e perdiam dinâmicas potenciadas. Nos diversos tempos se consolidavam ou re-equacionavam prioridades, se negociavam ou produziam novos canais relacionais.

Também outra especificidade destas aprendizagens se pode identificar no facto destas terem retirado muita da sua mais-valia da compreensão das próprias dinâmicas relacionais e processuais que se iam gerando, e de terem condicionado a escolha de instrumentais e procedimentos a esse mesmo conhecimento. Esta especificidade permitia simultaneamente que não se perdendo resultados de experiências entretanto encetadas, estas pudessem sempre ser reinventadas em função de novos contextos ou circunstâncias definidas pelos próprios processos relacionais em curso. Esta aposta numa aprendizagem dos processos permitiu que se mantivessem activas as potencialidades da unicidade dos momentos, dos espaços e dos restantes intervenientes na sua actualização.

Estas aprendizagens construíam-se, no entanto, num quadro de construção de uma cidadania activa, implicando ainda simultaneamente a gestão de conflitos de interesses e a consolidação de autonomias na gestão das proximidades em que estas diferenças conviviam. Não se tratava apenas de uma conciliação de interesses ou da angariação de "adeptos" em torno dos interesses mais fortes. Tratava-se precisamente de uma aprendizagem mútua dos diferentes actores envolvidos, capaz de saber lidar com interesses "naturalmente diferenciados", e "eventualmente conciliáveis" nessas mesmas diferenças. Eram, por isso, também, aprendizagens relacionais ganhas da decorrência 
da actualização dessas mesmas relações, marcadas pelo reconhecimento dos diferentes elementos participativos, dos seus estatutos e papéis, das suas regras de regulação, mas também da responsabilização e implicação colectiva na sua apropriação e produção a que a generatividade das suas dinâmicas induzia. O Poder, no seu uso e capacidade de exercício decorrente da sua própria actividade interventora no seio destes sistemas relacionais, encontrava nesta característica destas aprendizagens (a da gestão de diferenças em proximidade) uma das mais privilegiadas oportunidades para se manifestar e desenvolver em decorrência das dinâmicas generativas inerentes ao seu desenvolvimento processual.

Finalmente, mas por certo de não menor importância, importa referir ainda o carácter reflexivo destas mesmas aprendizagens ancorado na capacidade de produção de novos saberes, saber-fazer, poderes e saber-poder pela plasticidade que permitia à actualização dos conteúdos e sistemas de permanente reciclagem dos conhecimentos que ia produzindo. Obviamente que o uso sistemático de instrumentos formais de diagnóstico e avaliação apoiavam a sua permanente actualização. Importa, no entanto, evidenciar, neste processo, a adopção destes mecanismos reflexivos na quotidianeidade das práticas encetadas e sobretudo no espólio atitudinal que lhe presidia. Esta característica assumida na construção e gestão destes processos de aprendizagem viria sobretudo a optimizar a concertação construtiva e generativa dos seus sistemas relacionais, quer na credibilização das suas regras quer na legitimação dos diferentes contributos e da sua capacidade produtiva,

\section{Referências Bibliográficas}

BONETTI, M. (1994), "Révalorisation des quartiers en crise: de la réhabilitation à la gestion urbaine integrée", in Sociedade e Território, n. ${ }^{\circ}$ 20, pp. 17-25.

FREITAS, M. J. (1994), “Os paradoxos do Realojamento", in Sociedade e Território, n. ${ }^{\circ}$ 20, pp. 26-34.

FREITAS, M. J. (1995a), Princípios, Cenários e Estratégias de Intervenção para o PER/Cascais, Lisboa, LNEC, Relatório $312 / 95 /$ GES

FREITAS, M. J. e BRITO, V. (1996) - Quinta da Tainha Relatório $n^{o}$ 1: Pré-Diagnóstico, Lisboa, LNEC, Relatório 286 96/GES (Confidencial). independentemente dos riscos, incertezas, cenários de maior ou menor caoticidade com que se iam confrontando.

Este processo contou com cinco anos de exercício e a documentação para análise apresenta uma infinidade de potencialidades que por certo não foram completamente exploradas no âmbito deste texto. Importa também chamar a atenção que para além do carácter absolutamente renovador dos sistemas relacionais que encetou também estes se encontram naturalmente incompletos.

De facto se as condições de acolhimento referenciadas no início deste processo se encontram profundamente alteradas - quer em decorrência do seu próprio desenvolvimento, quer pelo legado de experiências e conhecimento que permitiu produzir sobre as exigências e a generatividade das suas dinâmicas relacionais, quer ainda pelo legado de novos instrumentais ao nível dos saber-fazer que para ele foram contribuindo - estas persistem em lembrar a sua viabilidade e a suas potencialidades para a prossecução deste projecto, para além da urgência e da necessidade da prossecução dos objectivos que justificaram o seu desenvolvimento. As especificidades em que este processo se veio a desenvolver enquanto processo relacional e generativo permitem, mesmo tratando ainda de um processo incompleto, identifica-lhes fortes e seguros alicerces ao desenvolvimento das suas dinâmicas. E qualquer que venha a ser o seu desenvolvimento, dificilmente poderão ser esquecidas as aprendizagens e as capacidades produtivas de poderes e autonomias que entretanto este processo ajudou a adquirir.

FREITAS, M. J. e RAMOS, T. (1995b), Bairro das Marianas - Relatório n. ${ }^{\circ}$ 1: Pré-Diagnóstico, Lisboa, LNEC, Relatório 354/95/GES (Confidencial).

FREITAS, M. J. (1998) - "Mobilising community resources" in A. Madanipour et al (Edts.) Social Exclusion in European Cities - Processes, Experiences and Responses, London, Jessica Kingsley Publishers, Col. Regional Policy and Development Series/23, 1. ${ }^{\text {a }}$ ed., pp. 211-234.

GUERRA, I. (1994) , “As pessoas não são coisas que se ponham em gavetas", Sociedade e Território, no 20, pp. 11-16. 